\title{
Combined Emission Economic Dispatch of Power System in Presence of Solar and Wind Using Flower Pollination Algorithm
}

\author{
ANUM ABID*, TAHIR NADEEM MALIK*, AND MUHAMMAD MANSOOR ASHRAF*
}

RECEIVED ON 16.04.2018 ACCEPTED ON 17.08.2018

\begin{abstract}
ED (Economic Dispatch) problem is one of the vital step in operational planning. It is a nonconvex constrained optimization problem. However, it is solved as convex problem by approximation of machine input/output characteristics, thus resulting in an inaccurate result. Reliable, secure and cheapest supply of electrical energy to the consumers is the prime objective in power system operational planning. Increase in fuel cost, reduction in fossil-fuel assets and ecological concerns have forced to integrate renewable energy resources in the generation mix. However, the instability of wind and solar power output affects the power network. For solution of such solar and wind integrated economic dispatch problems, evolutionary approaches are considered potential solution methodologies. These approaches are considered as potential solution methodologies for nonconvex ED problem. This paper presents CEED (Combined Emission Economic Dispatch) of a power system comprising of multiple solar, wind and thermal units using continuous and binary FPA(Flower Pollination Algorithm). Proposed algorithm is applied on 5, 6, 15, 26 and 40 thermal generators by integrating several solar and wind plants, for both convex and nonconvex ED problems. Proposed algorithm is simulated in MATLAB 2014b. Results of simulations, when compared with other approaches, show promise of the approach.
\end{abstract}

Key Words: Economic Dispatch, Flower Pollination Algorithm, Solar, Wind.

\section{INTRODUCTION}

$\int^{1}$ nergy is the currency of universe. Researchers in this world played a significant role for enhancement and growth of sustainable, reliable and clean energy systems for satisfying the necessities of large number of people and to minimize the usage of fossil fuels. Rapid growth of expenses of fuel, reduction in fossil fuel assets and environmental or ecological considerations, forced to integrate the AER (Alternative Energy Resources) in conventional generation systems.
$\mathrm{ED}[1]$ is a vital step in power system operational planning. Key goal of ED problem is to allocate power to the generators, to minimize operational fuel and emission cost, subject to all related operational constraints. It is a nonconvex constrained optimization problem. However, it has been addressed comprehensively in MP (Mathematical Programming) environment by converting it into convex problem. This is due to inability of the MP approaches to tackle nonconvex problems, except dynamic

Authors E-Mail: (anumabid24@gmail.com, tahir.nadeem@uettaxila.edu.pk,mansoor.ashraf@uettaxila.edu.pk)

* Department of Electrical Engineering, University of Engineering \& Technology, Taxila, Pakistan. 
programming which also suffers from the curse of dimensionality.

History of ED starts from 1920. In the start of 1930s, EICC (Equal Incremental Cost Criterion) was applied to obtain the best possible solutions. An overview of various methods, which were applied for the period of 1977-1988, for the solution of ED is presented in [2].

Conventional methods such as Lambda Iterative method [3], Gradient Search technique [4], Newton technique [5], Linear Programming [6] and Interior Point method [7] are used to solve convex problems.

Evolutionary approaches are potential solution methodologies for nonconvex ED problems. PSO (Particle Swarm Optimization) [8], Improved PSO [9], EnhancedAdaptive PSO, DEA(Differential Evolutionary Algorithm) [10], Hybrid Swarm Intelligence Search, Improved Cross Entropy Method [11], Bee Colony Optimization [12] and many others are used for nonconvex ED problems.

Electrical power system is an interrelated network and mainly depends on conventional sources of power production. Power sectors require amendments and developments for meeting the needs of large number of people. Nowadays, deployment of renewable energy resources is highly encouraged [13]. Efforts are being made, focusing on improvement in production of renewable energy while maintaining optimal scheduling of interrelated systems.

Rising trend in fuel cost, depletion of fossil energy reserves, and environmental concerns are the major factors to find alternate solutions for producing energy. Renewable energy resources are gaining popularity due to technological advancements in the field of solar and wind power. The solar and wind energy resources generate variable power output, due to changes in climate and weather conditions. The variations in generated power output makes economic dispatch, a random optimization problem and adds complexities in it. These complexities can be solved by evolutionary algorithms, to gain benefit, by reducing both the emission and fuel cost. Strength Pareto Evolutionary Algorithm has been used in [14], in which EED (Economic and Emission Dispatch) problem has been solved using one wind plant and a solar plant. Security constrained dynamic (EED) model has been presented in [15]. Modified Harmony Search Algorithm has been proposed in [16] for solving CEED (Combined Economic Emission Dispatch) incorporating practical constraints. CEED problem having photovoltaic generation has been solved using PSO in [2] considering power balance and power limits constraints.

FPA (Flower Pollination Algorithm) is an efficient evolutionary approach. It is a robust and reliable technique which is inspired by the fertilization mechanism of flowers. Its meta-heuristic nature can be applied to flourish new searching algorithms. FPA has potential to solve convex as well as nonconvex problems in an efficient way. It has a single significant parameter called Sp (Switching probability). Using this key parameter, the implementation of proposed algorithm becomes simpler and faster. Moreover, by switching between the global and local pollination, solution can be avoided from getting stuck at the local optimum.

In the recent past, researchers evaluated the efficiency of FPA and analyzed its characteristics in solving convex and nonconvex objective functions. Multi-objective optimization problem is solved by FPA in [17]. A modified FPA is given for optimization of global problems in [18].

This paper primarily focuses on a novel solution methodology that competently reduces the operational cost and emission using continuous and binary FPA. The aim of dealing with CEED in thermal generators is to 
maintain the optimal power sharing of a system that comprises of multiple solar, wind and thermal units. FPA deals with continuous random variables which are used for thermal units and binary FPA(BFPA) deals with binary random variables which are used for solar and wind units. The proposed technique analyzes the variable characteristics of solar radiations and speed of wind. The presented approach uses a switching probability to find solution of both convex and nonconvex problems. The presented paper also focuses on the concept of integration of renewable energy resources in the power system for reduction in both the operational cost and emissions. Thus optimal dispatch of the resources will lead to cheap, clean and environment friendly power production in the near future.

Five test cases are considered. Solar and wind units are integrated with 5, 6, 15, 26 and 40 thermal units. Results of simulations when compared with other approaches, prove that this technique out performs in solving CEED problem.

Rest of the paper is organized as follows: Section 2 contains the mathematical formulation of problem. Section 3 discusses the optimization algorithm to solve ED problem. Section 4 describes application of FPA and BFPA to solve ED problem. Section 5 describes case studies. Section 6 deals with the results and discussions. Section 7 concludes the paper.

\section{PROBLEM FORMULATION}

The ED of a power system with the integration of renewable energy has various operating constraints associated with different generating units. The objective function for CEED [19] is solved to minimize total cost of production, as given by Equation (1).

$$
\operatorname{Min}\left(F_{\text {total }}\right)=\sum_{g=1}^{1} F_{\text {ther }}\left(P_{g}\right)+\sum_{h=1}^{m} F_{s}\left(P_{h}\right)+\sum_{i=1}^{n} F_{w}\left(P_{i}\right)
$$

where $F_{\text {total }}$ is Total cost of production, $\sum_{\mathrm{g}=1}^{1} \mathrm{~F}_{\text {ther }}\left(\mathrm{P}_{\mathrm{g}}\right)$ is Total cost of thermal generators, $\sum_{h=1}^{m} F_{s}\left(P_{h}\right)$ is Total cost of solar units, and $\sum_{i=1}^{n} F_{w}\left(P_{i}\right)$ is Total cost of wind units.

Each model has its own cost associated with it. For thermal and wind plants, it depends on thermal and wind cost coefficients respectively while for solar plants, it depends on per unit cost of solar plant.

\subsection{Modeling of Thermal Plants}

Dispatch of thermal generators includes minimization of both fuel and emission cost which becomes a CEED problem [20]. Total cost of thermal generating plants includes fuel cost as well as emission cost.

$$
\sum_{\mathrm{g}=1}^{1} \mathrm{~F}_{\text {ther }}\left(\mathrm{P}_{\mathrm{g}}\right)+\sum_{\mathrm{h}=1}^{\mathrm{m}}\left(\left(\mathrm{H}_{\text {ther }}\right)\left(\mathrm{P}_{\mathrm{g}}\right)+\mathrm{E}_{\text {ther }}\left(\mathrm{P}_{\mathrm{g}}\right)\right)
$$

where $\mathrm{H}_{\text {ther }}\left(\mathrm{P}_{\mathrm{g}}\right)$ is Fuel cost of thermal generator, $\mathrm{E}_{\text {ther }}\left(\mathrm{P}_{\mathrm{g}}\right)$ is Emission cost of thermal generator.

Convex fuel cost characteristic of thermal generator is given by Equation (3).

$$
\mathrm{H}_{\text {ther }}\left(\mathrm{P}_{\mathrm{g}}\right)=\mathrm{a}_{\mathrm{g}} \mathrm{P}_{\mathrm{g}}^{2}+\mathrm{b}_{\mathrm{g}} \mathrm{P}_{\mathrm{g}}+\mathrm{c}_{\mathrm{g}}
$$

where $a_{g}, b_{g}$, and $c_{g}$ are the fuel cost coefficients of $g^{\text {th }}$ generating unit.

In nonconvex fuel cost functions, valve point effect is added in the characteristic equation. Nonconvex fuel cost characteristic of thermal generator is given by Equation (4).

$\mathrm{H}_{\text {ther }}\left(\mathrm{P}_{\mathrm{g}}\right)=\mathrm{a}_{\mathrm{g}} \mathrm{P}_{\mathrm{g}}^{2}+\mathrm{b}_{\mathrm{g}} \mathrm{P}_{\mathrm{g}}+\mathrm{c}_{\mathrm{g}}+\left|\mathrm{e}_{\mathrm{g}} * \sin \left(\mathrm{f}_{\mathrm{g}} *\left(\mathrm{P}_{\text {imin }}-\mathrm{P}_{\mathrm{i}}\right)\right)\right| \mathrm{US} \$ \mathrm{~h}$

where ag, $b_{g}, c_{g}, e_{g}$ and $f_{g}$ are the fuel cost coefficients of $\mathrm{g}^{\text {th }}$ generating unit. 
Emissions of thermal generator are given by Equation (5).

Emissions $=\mathrm{a}_{\mathrm{g}} \mathrm{P}_{\mathrm{g}}^{2}+\beta_{\mathrm{g}} \mathrm{P}_{\mathrm{g}}+\gamma_{\mathrm{g}}+\mu_{\mathrm{g}} * \exp \left(\delta_{\mathrm{g}} * \mathrm{P}_{\mathrm{g}}\right) \mathrm{kg} / \mathrm{h}$

where $\alpha_{\mathrm{g}}, \beta_{\mathrm{g}}, \gamma_{\mathrm{g}}, \mu_{\mathrm{g}}$ and $\delta_{\mathrm{g}}$ arethe emission coefficients of $\mathrm{g}^{\text {th }}$ generating unit.

Emission costs of thermal generator are given by Equation (6).

$\mathrm{E}_{\text {ther }}\left(\mathrm{P}_{\mathrm{g}}\right)=\mathrm{v}_{\mathrm{g}}\left(\alpha_{\mathrm{g}} \mathrm{P}_{\mathrm{g}}^{2}+\beta_{\mathrm{g}} \mathrm{P}_{\mathrm{g}}+\gamma_{\mathrm{g}}+\mu_{\mathrm{g}} * \exp \left(\delta_{\mathrm{g}} * \mathrm{P}_{\mathrm{g}}\right)\right) \mathrm{US} \$ / \mathrm{h}$

where $v_{g}$ represents the emission cost coefficient of $g^{\text {th }}$ generating unit.

For thermal plants, input variables are fuel and emission cost coefficients. Powers of individual generators are also input by random initialization taking into account ramp rate, power limits and power balance constraint and the best possible solution of power output is obtained at which the minimum cost (output) of production is achieved.

\subsection{Modeling of Solar Plants}

Power output produced by solar plant [20] is given by Equation(7).

$\mathrm{P}_{\mathrm{h}}=\frac{\mathrm{P}_{\text {rated }}}{1000}\left\{1+\beta\left(\mathrm{T}_{\mathrm{ref}}-\mathrm{T}_{\mathrm{amb}}\right)\right\} \times \mathrm{S}_{\mathrm{i}}$

where $\mathrm{P}_{\text {rated }}$ is Rated power, $\mathrm{T}_{\text {ref }}$ is Reference or fixed temperature of region, $\mathrm{T}_{\mathrm{amb}}$ is Ambient or variable temperature for a day, $\beta$ is Temperature coefficient, and $S_{t}$ is Incident photovoltaic radiation.

Solar share of $\mathrm{m}$ number of solar plants in the power system is given by [20].

Solar Share $=\sum_{\mathrm{h}=1}^{\mathrm{m}} \mathrm{P}_{\mathrm{h}} \times \mathrm{V}_{\mathrm{h}}$ where $\mathrm{P}_{\mathrm{h}}$ gives the power available in $\mathrm{h}^{\text {th }}$ solar plant and $\mathrm{V}_{\mathrm{h}}$ decides the working state of solar unit which is either 0 (OFF) or $1(\mathrm{ON})$.

From Equation (7), it is clear that power produced by solar plant varies with the solar radiations and temperature, but the plant was installed to work at its rated power. For maximum benefit, all solar units must be ON i.e. $V_{h}=1$ for each unit $h$, but since the power available at the output, changes in accordance with the temperature and solar radiations, there occurs a penalty cost for each solar unit which is called the per unit cost of each plant.

Cost of operation of $\mathrm{h}^{\text {th }}$ solar plant [2] to produce solar power $\mathrm{P}_{h}$ is given as:

$\mathrm{F}_{\mathrm{s}}\left(\mathrm{P}_{\mathrm{h}}\right)=\sum_{\mathrm{h}=1}^{\mathrm{m}} \mathrm{S}_{\mathrm{h}} \times \mathrm{P}_{\mathrm{h}} \times \mathrm{V}_{\mathrm{h}}$

where $S_{h}$ represents the per unit solar cost coefficient. Solar cost coefficient $S_{h}$ of each $h^{\text {th }}$ solar unit is given in US\$/MWh [2].This operation cost is associated with each unit that produces solar power $\mathrm{P}_{\mathrm{h}}$.

For solar plants, incident solar radiations and temperature of the area are input variables along with temperature coefficient. Output power produced by solar plants is used to find the solar share in the power system depending upon it's ON or OFF condition. As the power output from solar plant and per unit cost coefficient of solar plant may vary, overall cost of production of solar power can vary.

\subsection{Modeling of wind plants}

Cost of wind power plant [19] associated with scheduled power $\mathrm{P}_{\mathrm{i}}$ is given by:

$\mathrm{C}_{\mathrm{w}}\left(\mathrm{P}_{\mathrm{i}}\right)=\sum_{\mathrm{i}=1}^{\mathrm{m}} \tau_{\mathrm{h}} \times \mathrm{P}_{\mathrm{i}}$

where $\tau_{i}$ represents the wind power coefficient. 
Velocity or speed of wind is a varying parameter and power produced by the wind plant does not have a linear relationship with it. Wind value is given as input data for a certain hour of the day and the power output is computed. For wind plants, power output depends on speed of wind which is a variable parameter.As a result, output power from wind plant also varies. Probability density function of wind velocity is applied to calculate the scheduled wind power $\mathrm{P}_{\mathrm{i}}$ is a function of wind velocity [22]. Wind power is calculated from wind speed and is given as:

$P_{i}=\left\{\begin{array}{cc}0 & \left(v<v_{d}, v \geq v_{m}\right) \\ P_{i}^{R} & \left(v_{n} \leq v \leq v_{m}\right) \\ \frac{\left(v-v_{\text {in }}\right) P_{i}^{R}}{v_{r}-v_{\text {in }}} & \left(v_{d} \leq v<v_{n}\right)\end{array}\right.$

Four zones of operation of wind plant can be seen in Fig. 1. The integration of wind unit disturbs the security of the power system and affects its stability. It varies the spare capacity which accounts for spare capacity punishing cost [21]. Spare capacity is the spare or extra power which is due to difference in scheduled wind power that is produced by the plant and actual wind power that is delivered to the load. Actual power delivered to the load is less than the scheduled power due to practical losses of the system. This difference in power accounts for a penalty cost which is called spare capacity punishing cost. This cost is given by:

$\mathrm{C}_{\mathrm{RWi}}=\sum_{\mathrm{i}=1}^{\mathrm{n}} \mathrm{r}_{\mathrm{i}} \times\left(\mathrm{P}_{\mathrm{i}}-\mathrm{P}_{\mathrm{i}} \mathrm{act}\right)$

where $r_{i}$ is the spare capacity coefficient, $P_{i}$ is the scheduled wind power generation and $\mathrm{P}_{\mathrm{i}}$ act is the actual wind power that is delivered to the load. Spare capacity punishing cost is added to the cost given in Equation (10), to give the total cost such that:

$$
\begin{aligned}
& \mathrm{F}_{\mathrm{w}}\left(\mathrm{P}_{\mathrm{i}}\right)=\mathrm{C}_{\mathrm{w}}\left(\mathrm{P}_{\mathrm{i}}\right)+\mathrm{C}_{\mathrm{CRi}} \\
& \mathrm{F}_{\mathrm{w}}\left(\mathrm{P}_{\mathrm{i}}\right)=\sum_{\mathrm{i}=1}^{\mathrm{n}} \tau_{\mathrm{i}} * \mathrm{P}_{\mathrm{i}} \times \mathrm{P}_{\mathrm{i}}+\sum_{\mathrm{i}=1}^{\mathrm{n}} \mathrm{r}_{\mathrm{i}} \times\left(\mathrm{P}_{\mathrm{i}}-\mathrm{p}_{\mathrm{i}} \text { act }\right)
\end{aligned}
$$

\subsection{Constraints}

Constraints are basically, the real time limitations for producing the power. Cost is minimized taking into account all related constraints. This is because, if these constraints are violated, solutions will not be feasible. Following constraints are taken into account:

Power Balance with Transmission Line Losses: Power balance constraint is a fundamental constraint in ED problem. This constraint must be satisfied at any cost for the operation of power system. Generators must provide sufficient power to meet the load demand and losses in the transmission lines. On the other hand, if extra power is generated above the required value, cost of this power production has to be paid. Cost can be minimized by optimal scheduling of generators so that no extra power is generated. Total power produced by thermal, solar and wind plants must meet the total load demand as well as transmission lines losses.

$\mathrm{P}_{\mathrm{d}}+\mathrm{P}_{\text {loss }}=\sum_{\mathrm{g}=1}^{1} \mathrm{P}_{\text {thergi }}+\sum_{\mathrm{h}=1}^{\mathrm{m}} \mathrm{P}_{\mathrm{sh}}+\sum_{\mathrm{i}=1}^{\mathrm{n}} \mathrm{P}_{\mathrm{wi}}$

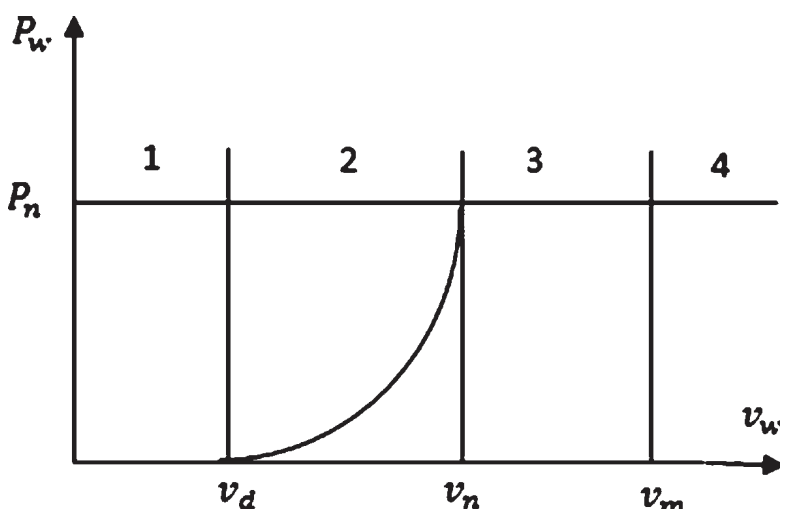

FIG. 1. FOUR ZONES OF WIND POWER OUTPUT 
where $\mathrm{P}_{\text {loss }}$ represents losses in transmission lines and these losses can be calculated using Equation (16).

$\mathrm{P}_{\text {loss }}=\sum_{\mathrm{s}=1}^{1}+\sum_{\mathrm{t}=1}^{1} \mathrm{P}_{\mathrm{s}} \mathrm{B}_{\mathrm{st}} \mathrm{P}_{\mathrm{t}}+\mathrm{B}_{\mathrm{s} 0} \mathrm{P}_{\mathrm{t}}+\mathrm{B}_{00}$

where $\mathrm{B}$ is the loss coefficient matrix.

Thermal Power Limits: Power limit constraint must be satisfied for operation of power system. The maximum generation of power is limited by the potential of a thermal unit to produce active power and minimum generation is limited by flame instability of furnace or boiler. If the output power of a generating unit is less than a pre-defined value $\mathrm{P}_{\mathrm{g}}$ min, then this generator is not connected to the bus bar since it is not feasible to produce a small value of active power from that generator. Therefore, the power which is produced, cannot voilate the limits of boundary. The problem is to find an optimal solution within the boundary, so that the cost is minimized. Power produced by thermal generators must be within their corresponding minimum and maximum limits.

$\mathrm{P}_{\mathrm{g}} \min \leq \mathrm{P}_{\mathrm{g}} \leq \mathrm{P}_{\mathrm{g}} \max$

Solar Power Balance: Output produced by solar plant is limited due to unpredictable intensity of solar radiations. Cost is minimized when maximum output is produced from the solar plant. Therefore, for solar plants, difference between the total power available by solar plant and the total solar share, must be minimum [20] such that:

$$
\sum_{h=1}^{m} P_{h}-\sum_{h=1}^{m} P_{h} \times V_{h}=0
$$

Wind Power Limits: Solution will not be feasible, if power limit constraint is not satisfied. Depending upon the capacity of wind plant, maximum power which is produced from the wind speed is limited. Similarly, if the wind unit violates the lower limit of power, the unit will not be connected to the system. This is because a very low value of power output is not feasible for the system. Cost is minimized by optimal scheduling of power within the generation limits. Power produced by wind plants must be in between lower and upper limits.

$\mathrm{P}_{\mathrm{wi}} \min \leq \mathrm{P}_{\mathrm{wi}}<\mathrm{P}_{\mathrm{wi}} \max$

Ramp Rate Constraint: The ramp rate constraint determines the limits, within which, the power produced by a particular generator may vary for each hour. These ramp rate limits are given by Equation set (20)

$$
\begin{aligned}
& \mathrm{P}_{\mathrm{g}}^{\mathrm{hr}}-\mathrm{P}_{\mathrm{g}}^{\mathrm{hr}-1} \leq \mathrm{UR}_{\mathrm{g}} \\
& \mathrm{P}_{\mathrm{g}}^{\mathrm{hr}-1}-\mathrm{P}_{\mathrm{g}}^{\mathrm{hr}} \leq \mathrm{DR}_{\mathrm{g}}
\end{aligned}
$$

where $\mathrm{UR}_{\mathrm{g}}$ and $\mathrm{DR}_{\mathrm{g}}$ are the up ramp limit and down ramp limit of $\mathrm{g}^{\text {th }}$ generating unit respectively while hr represents the hour or time in which the generator is in operation. The powerP ${ }_{\text {g }}^{\text {hr }}$ produced by the $\mathrm{g}^{\text {th }}$ unit in any hour may not exceed the power $\mathrm{p}_{\mathrm{g}}^{\mathrm{hr}-1}$ of previous hour, by more than a particular value $\mathrm{R}_{\mathrm{g}}$. Similarly, it should not be less than the power $\mathrm{P}_{\mathrm{g}}^{\mathrm{hr}} \mathrm{g}$ of previous hour, by more than a defined value $\mathrm{DR}_{\mathrm{g}}$. This is because a particular unit is not able to change its output power too rapidly due to limited thermal and mechanical stresses. Thus, taking into account this constraint, optimal power is given to each generator so that minimum cost is obtained.

Wind speed and solar radiations are random parameters. Power produced by wind and solar plants vary in accordance with these input parameters. Depending upon the uncertainties in the power output from solar and wind plant, power share of thermal plants varies, accounting for complex power balance and ramp rate constraint in the economic dispatch problem. Thus taking into account all these things, best solution for economic dispatch problem is proposed at which minimum cost of operation is achieved. 


\section{ALGORITHM FPA AND BFPA}

The CEED of a power system with the integration of renewable energy is a complex optimization problem. For thermal generators, random decision variables are continuous. For solar or wind plant, random decision variables are binary, possessing the value either 0 or 1. Algorithm used for optimization is described as follows:

\subsection{Flower Pollination Algorithm}

FPA is originated from the idea of fertilization process of flowers [17]. On the basis of global pollination, pollens are transmitted for cost-effective and energy-saving ED process. Based on local pollination, abiotic process is implemented for optimization problems. In local pollination process, pollens are transmitted by different mediums, such as birds, animals and wind.

All the features, constancy and behavior of FPA can be formulated as per following rules [23]:

(1) Cross pollination is considered as a global fertilization process, with pollinators doing levy flight. Self-pollination is considered as a local fertilization process of pollens. Flower constancy gives the probability of regeneration, which is related to the similarity in the two flowers involved in the pollination.

Pollination process is switched from the local to global pollination at a fixed probability $\mathrm{p} \in[0,1]$.

Plants can have large number of flowers, and each flower produces multiple pollen gametes. For simplicity, each plant is considered with a single flower and every single flower produces a single gamete. Hence, differentiation between plant, flower and pollen gamete is not required. Aforementioned consideration means that, solution of the problem can be a plant, flower or a pollen gamete. Global pollination is computed using Equation (21).

$\mathrm{y}_{\mathrm{i}}^{\mathrm{k}+1}=\mathrm{y}_{\mathrm{i}}^{\mathrm{k}}+\left(\mathrm{y}_{\mathrm{i}}^{\mathrm{k}}-\mathrm{g}_{\mathrm{b}}\right)$

where $\mathrm{i}$ represents any pollen, $\mathrm{y}_{\mathrm{i}}$ represents a solution vector at $\mathrm{k}^{\text {th }}$ iteration, and $\mathrm{g}_{\mathrm{b}}$ represents best solution among the set of feasible solutions in the present iteration. The factor L denotes a Levy function which gives the potential of pollination i.e. step length. As pollinators travel large distances with different step lengths, Levy flight is applied to characterize their movements effectively [20]. We have L $>0$ expressed as:

$$
\mathrm{L}=\operatorname{Levy}=\frac{\Gamma[\lambda] * \sin (\lambda \pi / 2)}{\pi *\left(\mathrm{D}^{\lambda+1}\right)},\left(\mathrm{D}>>\mathrm{D}_{0}>0\right)
$$

In Equation (22), $\Gamma(\lambda)$ defines the mathematical gamma function, and D represents large distances $\mathrm{D}>>\mathrm{D}_{0}>0$. Similarly, the local solution is computed using Equation (23).

$y_{i}^{k+1}=y_{i}^{k}+\in\left(y_{i}^{k}-y_{s}^{k}\right)$

where $\in$ denotes epsilon ranging between $[0,1]$ which gives a local but random walk. $\mathrm{y}_{\mathrm{r}}^{\mathrm{k}}$ and $\mathrm{y}_{\mathrm{s}}^{\mathrm{k}}$ are the solutions from various flowers of identical plants. Usually solutions are found by FPA at both the local and the global level. In neighboring flowers, pollens are expected to be transferred by local pollination. Pollens of flowers which are at large distances, are expected to be transferred by global pollination. Thus, the algorithm requires a switching probability $\mathrm{p} \in[0,10]$ to toggle between the local and global pollination. 


\subsection{Binary Flower Pollination Algorithm}

To solve binary random variables of solar and wind units, binary BFPA is applied. The stages of BFPA are identical to ordinary FPA, however, some changes are made, which are as follows:

Since the initial values in BFPA are binary, the initialization of flower is needed to be done, to fit in the binary position such as:

$\mathrm{Y}_{\mathrm{i}}=\left[\mathrm{Y}_{\mathrm{i} 1}, \mathrm{Y}_{\mathrm{i} 2}, \mathrm{Y}_{\mathrm{i} 3}, \ldots . . \mathrm{Y}_{\mathrm{iN}}\right] \forall \mathrm{Y}_{\mathrm{i} 1}, \mathrm{Y}_{\mathrm{i} 2}, \mathrm{Y}_{\mathrm{i} 3}, \ldots . \mathrm{Y}_{\mathrm{iN}} \in\{0,1\}$

A random boolean value is assigned to every unit of the flower as given by Equation (25).

$Y_{i c}=f_{p v}(y)=\left\{\begin{array}{cc}1 & \text { if } r \text { and }>0 \\ 0 & \text { Otherwise }\end{array}\right.$

Solutions are updated as given by Equation (26).

$\mathrm{Y}_{\mathrm{ic}}^{\mathrm{k}+1}=\left\{\begin{array}{cc}1 & \text { if } \mathrm{S}\left(\mathrm{Y}_{\mathrm{ic}}^{\mathrm{k}}\right)>\sigma \\ 0 & \text { Otherwise }\end{array}\right.$

where $\sigma$ is the random number, ranging from 0 to $1 . \mathrm{S}\left(\mathrm{Y}^{\mathrm{k}}{ }_{\mathrm{ic}}\right)$ defines the sigmoid function, used to scale new solutions between 0 and 1 . This function is computed using Equation (27).

$$
S\left(\mathrm{Y}_{\mathrm{ic}}^{\mathrm{k}}\right)=\frac{1}{1+e^{-Y_{i c}^{k}}}
$$

\section{ECONOMIC DISPATCH USING FPA AND BFPA}

FPA and BFPA are applied for EED of a power system integrated with renewable energy resources. For thermal units, initial control variables are continuous while for solar and wind units, these variables are binary. Flow chart shown in Fig. 2, describes the methodology to search the solution of the ED problem, using FPA and BFPA.
Application of algorithm for environmental constrained ED problem is presented by following pseudo code.
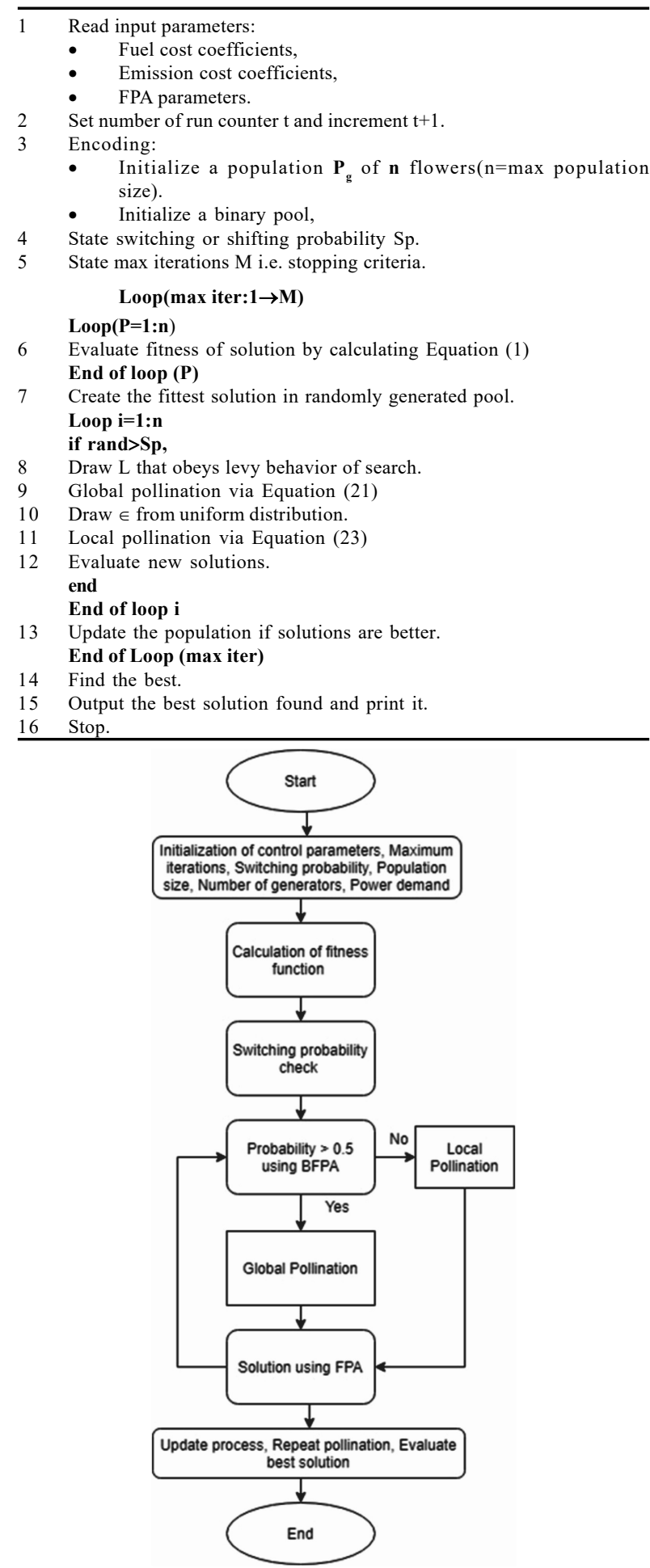

FIG. 2. FLOWCHART OF ALGORITHM USING FPA AND $B F P A$ 


\section{CASE STUDIES}

Five case studies, each having a standard test system, are used to verify the strength of FPA for handling the EED problem. Test system 1 and 3 have convex fuel cost curves while test system 2, 4 and 5 have non-convex fuel cost curves. Test systems used for the case studies, are briefly described as follows:

Test System-1: In test system 1, 6 thermal generators with convex fuel cost characteristics, transmission losses and ramp rate characteristics, are taken into account. 13 solar units and a wind plant of $1.62 \mathrm{MW}$, is integrated with the system. Data for the unit rate of solar plants, power demand and rated power of individual solar plant can be found in [2]. Data for wind speed and scheduled power output has been taken from Sapphire Wind Power Plant, Karachi, Pakistan and is given in Table 1. For all the test cases, data of wind plant are same.

Test System-2: In test system 2, solar and wind units are integrated with 5 thermal generators having nonconvex fuel cost characteristics [24]. Data for solar plant has been taken from [20].

TABLE 1. POWER DEMAND AND SAPPHIRE WIND POWER PLANT DATA

\begin{tabular}{|c|c|c|c|c|}
\hline \multirow[b]{2}{*}{ Hours } & \multicolumn{2}{|c|}{ Wind Data } & \multicolumn{2}{|c|}{ Power Demand } \\
\hline & $\begin{array}{c}\text { Speed } \\
(\mathrm{m} / \mathrm{s})\end{array}$ & \begin{tabular}{|c|} 
Actual Wind PowerDelivered to Load \\
(MW) \\
\end{tabular} & $\begin{array}{r}\text { Case-3 } \\
(\mathrm{MW}) \\
\end{array}$ & $\begin{array}{l}\text { Case-4 } \\
(\mathrm{MW})\end{array}$ \\
\hline 1 & 10.4 & 41 & 2600 & 2900 \\
\hline 2 & 9.7 & 35.7 & 2610 & 2901 \\
\hline 3 & 10 & 38.9 & 2620 & 2902 \\
\hline 4 & 11.1 & 42.5 & 2630 & 2906 \\
\hline 5 & 11.4 & 46.8 & 2640 & 2904 \\
\hline 6 & 12.2 & 50.6 & 2650 & 2905 \\
\hline 7 & 14.7 & 51.7 & 2660 & 2908 \\
\hline 8 & 16 & 50.9 & 2650 & 2904 \\
\hline 9 & 15.7 & 53.4 & 2640 & 2908 \\
\hline 10 & 15 & 51.8 & 2630 & 2900 \\
\hline 11 & 15.9 & 51.8 & 2620 & 2901 \\
\hline 12 & 14.7 & 50.7 & 2610 & 2902 \\
\hline 13 & 13.1 & 49.7 & 2620 & 2906 \\
\hline 14 & 13.4 & 49.9 & 2600 & 2904 \\
\hline 15 & 13.4 & 48.5 & 2610 & 2905 \\
\hline 16 & 12.7 & 46.7 & 2620 & 2908 \\
\hline 17 & 12.5 & 49.9 & 2630 & 2904 \\
\hline 18 & 11.9 & 47 & 2640 & 2908 \\
\hline 19 & 10.9 & 42.9 & 2650 & 2900 \\
\hline 20 & 10.8 & 40.7 & 2660 & 2901 \\
\hline 21 & 10.2 & 38.8 & 2650 & 2902 \\
\hline 22 & 9.9 & 37.7 & 2640 & 2906 \\
\hline 23 & 10.5 & 38.9 & 2630 & 2904 \\
\hline 24 & 10.5 & 38.9 & 2620 & 2905 \\
\hline
\end{tabular}

Mehran University Research Journal of Engineering \& Technology, Volume 38, No. 3, July, 2019 [p-ISSN: 0254-7821, e-ISSN: 2413-7219] 
Test System-3: In test system 3, 15 thermal generators with convex fuel cost curves [25], 13 solar units [2] and a wind power plant are considered. Power demand data for 24 hours are given in Table 1.

Test System-4: In test system 4, 26 thermal generators having nonconvex fuel cost curves [19], 13 solar units [2] and a wind power plant are taken into account. Table 1 gives the data for power demand.

Test System-5: In test system 5, 40 thermal units having nonconvex fuel cost curves [26] are considered. A solar plant rated at $1000 \mathrm{MW}$ and a wind plant are considered. Power demand of $10000 \mathrm{MW}$ is taken into account. Termination criteria for algorithm is the total number of iterations. Best results after 30 runs have been recorded. The graphs of each case study show the pattern of minimum cost of each hour. The power produced after satisfying all the constraints is the optimal and best possible solution at which minimum cost is obtained.

Table 2 gives the cost characteristics of generating units and algorithm parameters which are used to provide optimum results.

\section{RESULTS AND DISCUSSION}

Best results of power shares of all the generators give the minimum solar, wind and thermal costs. Results and discussions of each case study are presented in the following section:
Case Study-1: FPA is tested on test system 1 in which 6 thermal generators with convex fuel cost curves are used. It satisfies equality and inequality constraints. Solar unit switching status can be found in Table 3 where it can be seen that, all of these units will be off when there is zero solar radiation i.e. during night time. Table 4 gives the optimum results of power shares of generators and losses in transmission lines for 24 hours. Minimum fuel cost, emission cost, solar cost and wind cost in $\$ / \mathrm{hr}$ for 24 hours are given in Table 5. Minimum emissions of generators in $\mathrm{kg} / \mathrm{hr}$ can also be found in Table 5. Total cost of each hour reported in [2], where only solar plants were integrated to thermal generators, is compared with the total cost of each hour found using proposed FPA. This comparison proves that the integration of wind plant to the system considerably reduces the operational cost to its minimum. existing algorithms.

Fig. 3 shows the effect of renewable power share on fuel and emission cost. Depending upon solar radiations and wind speed, power output from these units varies. As the power output for these units increases for almost half the day, power share of thermal generators decreases. As a result, both the fuel and emission cost decrease. Fig. 3 shows that, larger renewable share results in lower fuel and emission cost. Emission cost for each hour is slightly less than fuel cost. Average cost comparison is given in Table 6. It represents that, cost over 24 hours is $31,596.95$ $\mathrm{US} \$ \mathrm{~h}$, which is significantly less than $38,807.167 \mathrm{US} \$ / \mathrm{h}$, given in [2]. For each hour, total cost calculated by using FPA is compared with the cost computed by using PSO [2]. This comparison can be seen in Fig. 4. It significantly demonstrates the success of FPA over.

TABLE 2. MACHINES CHARACTERISTICS AND FPA PARAMETERS

\begin{tabular}{|c|c|c|c|}
\hline No. & Components & Characteristics & Value \\
\hline \multirow{2}{*}{1.} & Algorithm Parameters & Total iterations Switching probability & 0.5 \\
& & Uniform distribution & {$[0,1]$} \\
\hline 2. & PV panel & Temperature. coefficient $\beta$ Ambient Temperature & -0.0025 \\
\hline \multirow{2}{*}{3.} & \multirow{2}{*}{ Wind plant } & Total number of turbines Wind power coefficient & $25^{\circ} \mathrm{C}$ \\
& & Spare capacity coefficient & 33 \\
& & & 150 \\
\hline
\end{tabular}

Mehran University Research Journal of Engineering \& Technology, Volume 38, No. 3, July, 2019 [p-ISSN: 0254-7821, e-ISSN: 2413-7219] 
TABLE 3. SOLAR UNIT SWITCHING STATUS- CASE STUDY-1

\begin{tabular}{|c|c|c|c|c|c|c|c|c|c|c|c|c|c|}
\hline Hour & \multicolumn{10}{|c|}{ Solar Unit Condition } \\
\hline 5 & 0 & 1 & 0 & 1 & 1 & 0 & 0 & 0 & 0 & 1 & 1 & 0 & 0 \\
\hline 6 & 0 & 0 & 0 & 0 & 1 & 0 & 0 & 0 & 0 & 0 & 1 & 0 & 0 \\
\hline 7 & 0 & 0 & 1 & 1 & 0 & 0 & 0 & 0 & 1 & 1 & 0 & 0 & 0 \\
\hline 8 & 0 & 1 & 1 & 0 & 1 & 1 & 1 & 0 & 1 & 0 & 1 & 1 & 1 \\
\hline 9 & 0 & 0 & 1 & 1 & 1 & 0 & 0 & 0 & 1 & 1 & 1 & 0 & 0 \\
\hline 10 & 1 & 0 & 0 & 1 & 1 & 1 & 1 & 1 & 0 & 1 & 1 & 1 & 1 \\
\hline 11 & 0 & 0 & 1 & 0 & 1 & 1 & 0 & 0 & 1 & 0 & 1 & 1 & 0 \\
\hline 12 & 1 & 1 & 0 & 1 & 1 & 1 & 1 & 1 & 0 & 1 & 1 & 1 & 1 \\
\hline 13 & 0 & 0 & 0 & 1 & 0 & 1 & 1 & 0 & 0 & 1 & 0 & 1 & 1 \\
\hline 14 & 0 & 0 & 0 & 1 & 1 & 1 & 1 & 1 & 0 & 1 & 1 & 1 & 1 \\
\hline 15 & 1 & 1 & 1 & 0 & 1 & 0 & 0 & 0 & 1 & 0 & 1 & 0 & 0 \\
\hline 16 & 1 & 1 & 1 & 1 & 1 & 0 & 0 & 0 & 1 & 1 & 1 & 0 & 0 \\
\hline 17 & 0 & 0 & 0 & 0 & 0 & 1 & 1 & 0 & 0 & 0 & 0 & 1 & 1 \\
\hline 18 & 0 & 0 & 0 & 0 & 0 & 0 & 0 & 1 & 0 & 0 & 0 & 0 & 0 \\
\hline 19 & 0 & 0 & 1 & 1 & 0 & 0 & 0 & 1 & 1 & 1 & 0 & 0 & 0 \\
\hline
\end{tabular}

TABLE 4. OPTIMUM POWER OUTPUT RESULTS-CASE STUDY 1

\begin{tabular}{|c|c|c|c|c|c|c|c|c|c|}
\hline Hour & $\begin{array}{c}\text { P1 } \\
\text { (MW) }\end{array}$ & $\begin{array}{c}\mathrm{P} 2 \\
(\mathrm{MW}) \\
\end{array}$ & $\begin{array}{c}\text { P3 } \\
\text { (MW) }\end{array}$ & $\begin{array}{c}\text { P4 } \\
\text { (MW) } \\
\end{array}$ & $\begin{array}{c}\text { P5 } \\
\text { (MW) }\end{array}$ & $\begin{array}{c}\text { P6 } \\
\text { (MW) }\end{array}$ & $\begin{array}{l}\begin{array}{l}\text { Ploss } \\
\text { (MW) }\end{array} \\
\end{array}$ & $\begin{array}{c}\text { PS } \\
(\mathrm{MW}) \\
\end{array}$ & $\begin{array}{l}\mathrm{PW} \\
(\mathrm{MW})\end{array}$ \\
\hline 1 & 392 & 52 & 186 & 126 & 70 & 86 & 2.4 & 0 & 42.9 \\
\hline 2 & 400 & 102 & 89 & 90 & 120 & 104 & 2.1 & 0 & 37.7 \\
\hline 3 & 377 & 152 & 122 & 96 & 65 & 101 & 2.6 & 0 & 39.6 \\
\hline 4 & 257 & 185 & 187 & 79 & 60 & 116 & 2.7 & 0 & 46.7 \\
\hline 5 & 337 & 191 & 95 & 97 & 110 & 56 & 2.9 & 2.2 & 48.2 \\
\hline 6 & 281 & 120 & 160 & 55 & 160 & 95 & 3.1 & 40 & 51.3 \\
\hline 7 & 288 & 97 & 136 & 88 & 129 & 93 & 2.7 & 104 & 53.4 \\
\hline 8 & 168 & 80 & 201 & 119 & 131 & 56 & 1.9 & 213 & 53.4 \\
\hline 9 & 248 & 130 & 206 & 68 & 119 & 74 & 2.5 & 228 & 53.4 \\
\hline 10 & 198 & 143 & 134 & 76 & 89 & 113 & 1.3 & 341 & 53.4 \\
\hline 11 & 212 & 136 & 149 & 58 & 102 & 59 & 2.1 & 430 & 53.4 \\
\hline 12 & 270 & 150 & 104 & 86 & 59 & 57 & 2.5 & 454 & 53.4 \\
\hline 13 & 283 & 79 & 97 & 72 & 109 & 63 & 1.7 & 432 & 52.6 \\
\hline 14 & 251 & 66 & 162 & 122 & 150 & 108 & 1.7 & 337 & 52.9 \\
\hline 15 & 292 & 109 & 190 & 123 & 78 & 106 & 1.8 & 310 & 52.9 \\
\hline 16 & 372 & 157 & 94 & 94 & 128 & 89. & 2.1 & 262 & 52.1 \\
\hline 17 & 452 & 109 & 159 & 126 & 116 & 51 & 2.3 & 155 & 51.8 \\
\hline 18 & 455 & 96 & 209 & 79 & 127 & 101 & 1.7 & 83 & 50.6 \\
\hline 19 & 410 & 146 & 242 & 58 & 124 & 118 & 2.6 & 15 & 45.6 \\
\hline 20 & 373 & 75 & 224 & 108 & 152 & 115 & 3.3 & 0 & 44.9 \\
\hline 21 & 410 & 125 & 149 & 130 & 97 & 71 & 2.4 & 0 & 41.3 \\
\hline 22 & 328 & 88 & 196 & 81 & 147 & 105 & 2.2 & 0 & 38.8 \\
\hline 23 & 372 & 100 & 159 & 122 & 95 & 85 & 2.9 & 0 & 43.2 \\
\hline 24 & 452 & 150 & 107 & 69 & 88 & 51 & 1.7 & 0 & 43.4 \\
\hline
\end{tabular}


Combined Emission Economic Dispatch of Power System in Presence of Solar and Wind Using Flower Pollination Algorithm

TABLE 5. BEST RESULTS OF COSTS AND EMISSIONS - CASE STUDY 1

\begin{tabular}{|c|c|c|c|c|c|c|}
\hline Hour & $\begin{array}{c}\begin{array}{c}\text { Fuel Cost } \\
(\mathrm{x} 104)\end{array} \\
\end{array}$ & $\begin{array}{c}\text { Emission cost } \\
(\mathrm{x} 103)\end{array}$ & $\begin{array}{c}\text { Solar Cost } \\
\text { (x103) }\end{array}$ & $\begin{array}{c}\text { Wind Cost } \\
(\mathrm{x} 103) \\
\end{array}$ & $\begin{array}{c}\text { Total Cost } \\
(\mathrm{x} 105) \\
\end{array}$ & $\begin{array}{c}\text { Emissions }(\mathrm{kg} / \mathrm{h}) \\
(\mathrm{x} 103)\end{array}$ \\
\hline 1 & 1.08 & 1.37 & - & 4.48 & 0.166 & 1.14 \\
\hline 2 & 1.07 & 1.30 & - & 3.86 & 0.159 & 1.08 \\
\hline 3 & 1.09 & 1.30 & - & 4.08 & 0.162 & 1.08 \\
\hline 4 & 1.05 & 1.06 & - & 5.09 & 0.167 & 0.88 \\
\hline 5 & 1.05 & 1.20 & 0.23 & 4.97 & 0.16 & 1.00 \\
\hline 6 & 1.02 & 0.99 & 4.11 & 5.20 & 0.20 & 0.82 \\
\hline 7 & 0.98 & 0.92 & 10.85 & 5.52 & 0.27 & 0.77 \\
\hline 8 & 0.90 & 0.74 & 21.89 & 5.60 & 0.37 & 0.62 \\
\hline 9 & 0.99 & 0.97 & 23.66 & 5.35 & 0.39 & 0.81 \\
\hline 10 & 0.91 & 0.71 & 35.32 & 5.54 & 0.50 & 0.59 \\
\hline 11 & 0.85 & 0.74 & 44.83 & 5.51 & 0.59 & 0.62 \\
\hline 12 & 0.87 & 0.87 & 47.32 & 5.62 & 0.62 & 0.72 \\
\hline 13 & 0.83 & 0.80 & 44.75 & 5.57 & 0.59 & 0.67 \\
\hline 14 & 1.01 & 0.88 & 35.09 & 5.59 & 0.51 & 0.73 \\
\hline 15 & 1.06 & 1.083 & 32.09 & 5.73 & 0.49 & 0.90 \\
\hline 16 & 1.11 & 1.290 & 27.35 & 5.71 & 0.45 & 1.07 \\
\hline 17 & 1.19 & 1.684 & 16.21 & 5.39 & 0.35 & 1.40 \\
\hline 18 & 1.26 & 1.768 & 8.601 & 5.39 & 0.28 & 1.47 \\
\hline 19 & 1.29 & 1.731 & 1.64 & 4.83 & 0.21 & 1.44 \\
\hline 20 & 1.23 & 1.469 & - & 4.92 & 0.18 & 1.22 \\
\hline 21 & 1.162 & 1.484 & - & 4.38 & 017 & 1.23 \\
\hline 22 & 1.10 & 1.193 & - & 4.00 & 0.16 & 0.99 \\
\hline 23 & 1.101 & 1.292 & - & 4.76 & 0.17 & 1.07 \\
\hline 24 & 1.091 & 1.602 & - & 4.79 & 0.173 & 1.33 \\
\hline
\end{tabular}

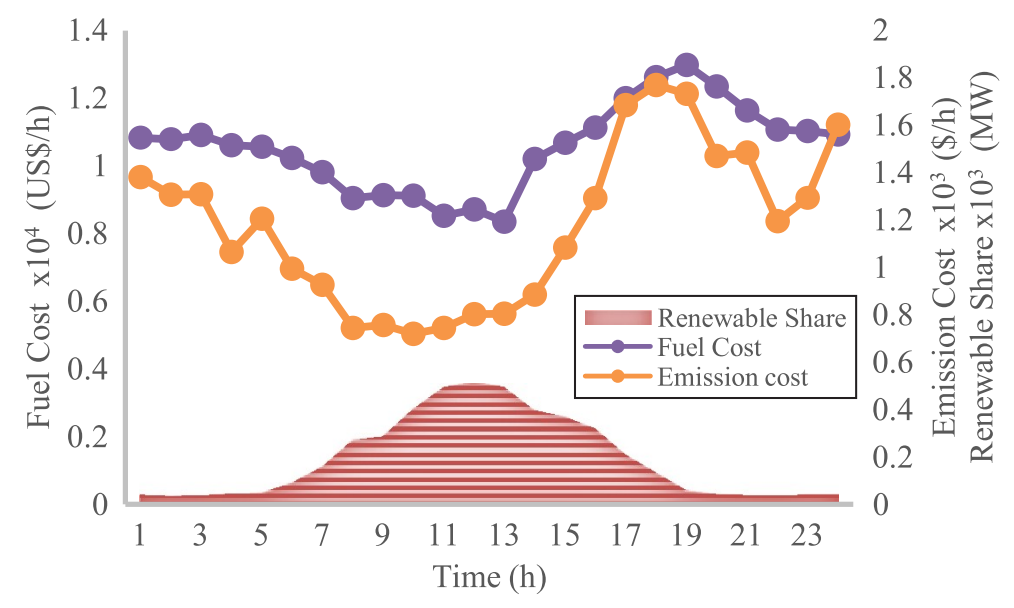

FIG. 3. EFFECT OF RENEWABLE SHARE ON FUEL AND EMISSION COST-CASE STUDY-1

TABLE 6. COST REDUCTION BY WIND INTEGRATION

\begin{tabular}{|c|c|c|c|}
\hline Test Case-1 & Solar-Thermal & Solar-Thermal-Wind & Cost Reduction (\%) \\
\hline Cost $(\mathrm{US} \$ \mathrm{~h})$ & $38,807.167$ & $31,596.95$ & 18.5 \\
\hline
\end{tabular}

Mehran University Research Journal of Engineering \& Technology, Volume 38, No. 3, July, 2019 [p-ISSN: 0254-7821, e-ISSN: 2413-7219] 
Case Study-2: Best results of test case 2, in which five thermal generators with nonconvex fuel cost curves have been used, are given in Table 7. These thermal generators have nonconvex fuel cost characteristics. Flower pollination algorithm is efficient in solving nonconvex and complex problems, subject to inequality and emission constraints. Fig. 5 shows the results of fuel and emission cost for 24 hours. It shows that, when maximum power is produced by solar and wind plants, minimum fuel and emission costs are achieved. At hour 12, power output from solar plant is maximum due to maximum solar radiations. Thus, renewable share has its peak value at midday. Fuel and emission cost is drastically cut to its minimum when the peak of renewable share appears in Fig. 5.

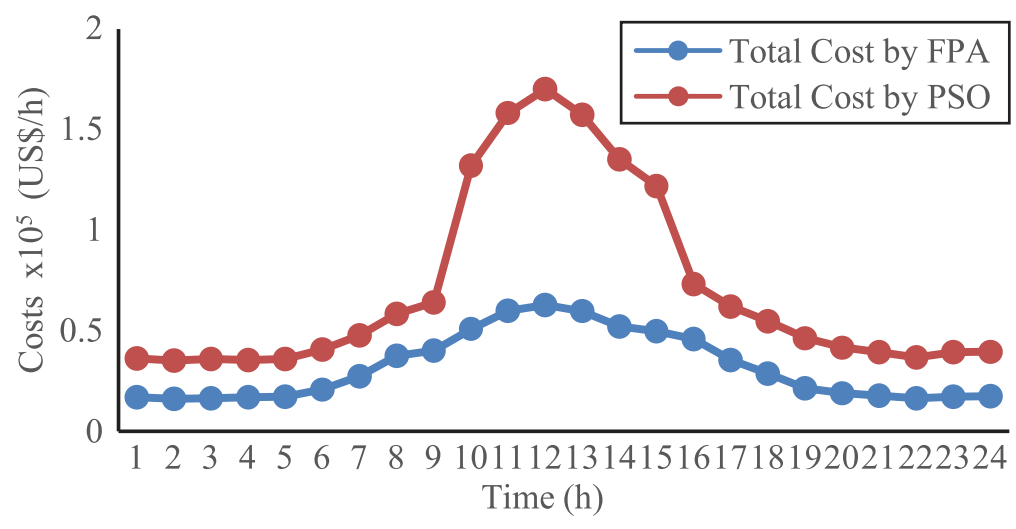

FIG. 4. COST COMPARISON - FPA VS PSO- CASE STUDY-1

TABLE 7. OPTIMUM POWER OUTPUTS, COSTS AND EMISSIONS- CASE STUDY-2

\begin{tabular}{|c|c|c|c|c|c|c|c|c|c|c|c|c|c|c|}
\hline \multirow[b]{2}{*}{ Hour } & \multicolumn{8}{|c|}{ Power Shares of Thermal and Renewable Generators (MW) } & \multicolumn{5}{|c|}{ Costs(US\$/h) } & \multirow{2}{*}{$\begin{array}{c}\text { Emissions } \\
(\mathrm{kg} / \mathrm{h}) \\
\left(\mathrm{x} 10^{3}\right)\end{array}$} \\
\hline & P1 & $\mathrm{P} 2$ & P3 & P4 & P5 & $\mathrm{P}_{\text {loss }}$ & $\mathrm{P}_{\mathrm{S}}$ & $\mathrm{P}_{\mathrm{w}}$ & $\begin{array}{l}\text { Fuel Cost } \\
\left(\times 10^{4}\right)\end{array}$ & \begin{tabular}{|c|} 
Emission \\
Cost \\
$\left(\mathrm{x} 10^{3}\right)$ \\
\end{tabular} & $\begin{array}{c}\text { Solar } \\
\text { Cost } \\
\left(\mathrm{x} 10^{3}\right) \\
\end{array}$ & $\begin{array}{l}\text { Wind } \\
\text { Cost } \\
\left(\mathrm{x} 10^{3}\right) \\
\end{array}$ & $\begin{array}{c}\text { Total } \\
\text { Cost } \\
\left(\mathrm{x} 10^{5}\right) \\
\end{array}$ & \\
\hline 1 & 75 & 103 & 40 & 43 & 108 & 2.1 & 0 & 43 & 2.468 & 0.4063 & -- & 4.483 & 0.033 & 0.338 \\
\hline 2 & 48 & 83 & 47 & 93 & 130 & 2.9 & 0 & 37 & 2.811 & 0.3298 & -- & 3.864 & 0.035 & 0.272 \\
\hline 3 & 75 & 53 & 86 & 143 & 80 & 2.1 & 0 & 40 & 3.089 & 0.4486 & -- & 4.085 & 0.039 & 0.373 \\
\hline 4 & 75 & 60 & 126 & 93 & 130 & 1.4 & 0 & 47 & 3.495 & 0.4572 & -- & 5.097 & 0.044 & 0.381 \\
\hline 5 & 75 & 48 & 88 & 143 & 156 & 2.9 & 2 & 48 & 3.762 & 0.4334 & 0.386 & 4.9741 & 0.050 & 0.361 \\
\hline 6 & 75 & 55 & 128 & 93 & 164 & 2.9 & 46 & 51 & 3.773 & 0.4552 & 7.882 & 5.200 & 0.126 & 0.379 \\
\hline 7 & 45 & 25 & 88 & 140 & 172 & 2.4 & 105 & 53 & 3.489 & 0.3615 & 18.15 & 5.5212 & 0.225 & 0.301 \\
\hline 8 & 15 & 21 & 128 & 93 & 122 & 2.6 & 224 & 53 & 2.721 & 0.3674 & 38.412 & 5.604 & 0.420 & 0.306 \\
\hline 9 & 10 & 20 & 88 & 131 & 172 & 2.0 & 218 & 53 & 3.136 & 0.3316 & 37.45 & 5.3503 & 0.414 & 0.276 \\
\hline 10 & 10 & 20 & 69 & 105 & 122 & 1.4 & 326 & 53 & 2.290 & 0.2644 & 55.913 & 5.514 & 0.590 & 0.220 \\
\hline 11 & 10 & 20 & 30 & 55 & 75 & 1.8 & 478 & 53 & 1.099 & 0.2267 & 82.69 & 5.5154 & 0.845 & 0.188 \\
\hline 12 & 10 & 20 & 30 & 40 & 90 & 1.9 & 498 & 53 & 1.105 & 0.2176 & 86.124 & 5.623 & 0.880 & 0.181 \\
\hline 13 & 10 & 20 & 30 & 40 & 140 & 2.0 & 413 & 53 & 1.563 & 0.2077 & 70.83 & 5.5705 & 0.731 & 0.173 \\
\hline 14 & 10 & 20 & 30 & 40 & 165 & 2.1 & 374 & 53 & 1.790 & 0.2094 & 64.735 & 5.594 & 0.672 & 0.174 \\
\hline 15 & 10 & 20 & 30 & 62 & 187 & 4.1 & 296 & 53 & 2.189 & 0.2230 & 51.29 & 5.7336 & 0.542 & 0.185 \\
\hline 16 & 10 & 20 & 30 & 40 & 142 & 2.2 & 288 & 52 & 1.579 & 0.2077 & 49.785 & 5.771 & 0.521 & 0.173 \\
\hline 17 & 10 & 20 & 30 & 90 & 187 & 3.4 & 172 & 52 & 2.550 & 0.2605 & 27.39 & 5.3896 & 0.307 & 0.217 \\
\hline 18 & 10 & 20 & 67 & 139 & 237 & 3.0 & 88 & 50 & 3.64 & 0.378 & 15.08 & 5.395 & 0.19 & 0.315 \\
\hline 19 & 40 & 50 & 107 & 189 & 209 & 2.3 & 16 & 46 & 4.595 & 0.5660 & 0.722 & 4.8315 & 0.083 & 0.471 \\
\hline 20 & 45 & 71 & 107 & 219 & 219 & 1.8 & 0 & 45 & 5.158 & 0.7286 & -- & 4.922 & 0.063 & 0.607 \\
\hline 21 & 43 & 101 & 73 & 169 & 256 & 2.8 & 0 & 41 & 4.992 & 0.6349 & -- & 4.3895 & 0.060 & 0.529 \\
\hline 22 & 13 & 95 & 60 & 196 & 206 & 3.2 & 0 & 39 & 4.404 & 0.6036 & -- & 4.001 & 0.054 & 0.503 \\
\hline 23 & 10 & 65 & 32 & 146 & 234 & 2.2 & 0 & 43 & 3.728 & 0.4782 & -- & 4.7674 & 0.046 & 0.351 \\
\hline 24 & 10 & 35 & 47 & 96 & 234 & 2.2 & 0 & 43 & 3.185 & 0.3980 & -- & 4.792 & 0.040 & 0.249 \\
\hline
\end{tabular}

Mehran University Research Journal of Engineering \& Technology, Volume 38, No. 3, July, 2019 [p-ISSN: 0254-7821, e-ISSN: 2413-7219] 
Case Study-3: For test case 3, in which 15 generating units with convex fuel cost curve have been used, optimum simulation results can be found in Table 8 . Cost obtained by using FPA is $30,360.875 \mathrm{US} \$ / \mathrm{h}$ which is $7.5 \%$ less than the cost obtained by Chaotic PSO [25]. Cost comparison can be found inTable 9. Fig. 6 shows that, increase in the power output from renewable energy resources, causes the decrease in the total cost of the system. For half of the day, power output from renewable energy resources is more, with its maximum value at midday. Fig. 6 shows that the total cost is reduced to its minimum, at peak hours.

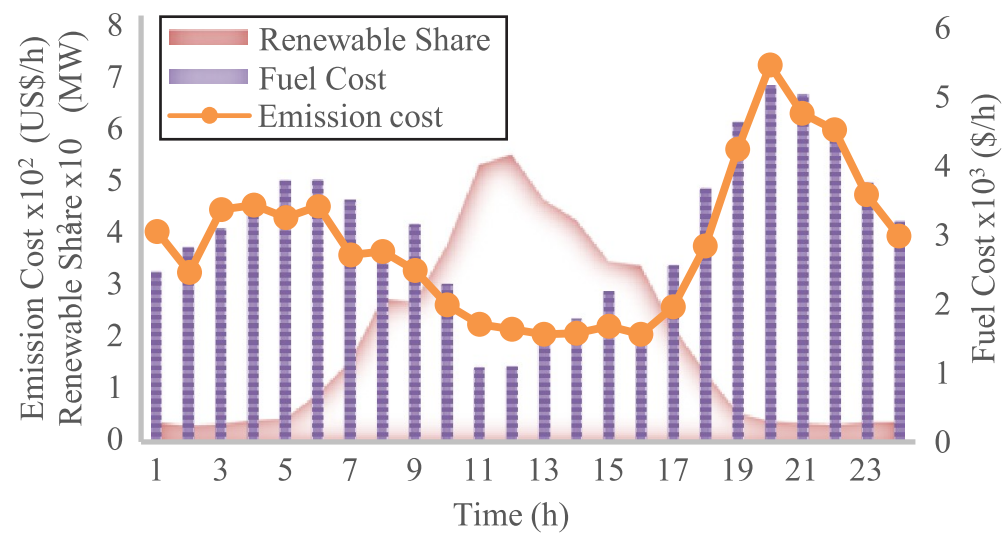

FIG. 5. EFFECT OF RENEWABLE ON FUEL \& EMISSION COST- CASE STUDY-2

TABLE 8. OPTIMUM RENEWABLE SHARE AND COSTS - CASE STUDY-3

\begin{tabular}{|c|c|c|c|c|}
\hline Hours & Fuel Cost (US\$/h) (x103) & Solar Cost (US\$/h) x103 & Wind Cost (US\$/h) (x102) & $\begin{array}{c}\text { Total Cost US(US\$/h) } \\
(\mathrm{x} 104)\end{array}$ \\
\hline 1 & 3.2231 & $\tilde{\mathrm{N}}$ & 0.525 & 3.228 \\
\hline 2 & 3.2003 & $\tilde{\mathrm{N}}$ & 0.445 & 3.204 \\
\hline 3 & 3.2412 & $\tilde{\mathrm{N}}$ & 0.448 & 3.245 \\
\hline 4 & 3.2119 & $\tilde{\mathrm{N}}$ & 0.678 & 3.218 \\
\hline 5 & 3.2288 & 0.0008 & 0.556 & 3.234 \\
\hline 6 & 3.2011 & 0.015 & 0.548 & 3.208 \\
\hline 7 & 3.1181 & 0.0342 & 0.622 & 3.127 \\
\hline 8 & 2.9300 & 0.081 & 0.663 & 2.944 \\
\hline 9 & 2.8954 & 0.0862 & 0.536 & 2.909 \\
\hline 10 & 2.7504 & 0.119 & 0.618 & 2.768 \\
\hline 11 & 2.5676 & 0.1602 & 0.619 & 2.589 \\
\hline 12 & 2.5546 & 0.166 & 0.673 & 2.578 \\
\hline 13 & 2.5930 & 0.1492 & 0.677 & 2.614 \\
\hline 14 & 2.7264 & 0.113 & 0.680 & 2.744 \\
\hline 15 & 2.7742 & 0.1072 & 0.749 & 2.792 \\
\hline 16 & 2.8433 & 0.096 & 0.798 & 2.861 \\
\hline 17 & 3.0046 & 0.0583 & 0.619 & 3.016 \\
\hline 18 & 3.1092 & 0.031 & 0.679 & 3.119 \\
\hline 19 & 3.2307 & 0.005 & 0.591 & 3.237 \\
\hline 20 & 3.2670 & $\tilde{\mathrm{N}}$ & 0.662 & 3.273 \\
\hline 21 & 3.2431 & $\tilde{\mathrm{N}}$ & 0.541 & 3.248 \\
\hline 22 & 3.2562 & $\tilde{\mathrm{N}}$ & 0.445 & 3.260 \\
\hline 23 & 3.2218 & $\tilde{\mathrm{N}}$ & 0.653 & 3.228 \\
\hline 24 & 3.2023 & $\tilde{\mathrm{N}}$ & 0.659 & 3.208 \\
\hline
\end{tabular}

Mehran University Research Journal of Engineering \& Technology, Volume 38, No. 3, July, 2019 [p-ISSN: 0254-7821, e-ISSN: 2413-7219] 
Fig. 7 shows the convergence of algorithm for the increased number of iterations and depicts the efficiency of FPA. As the number of iterations are increased, algorithm goes towards convergence and the cost attains a constant value after 120 iterations.

Case Study-4: In this test case, 26 generating units having nonconvex fuel cost characteristics have been used and emission economic dispatch of power system is solved. For this test case, cost obtained over 24 hours is $40,154.63 \mathrm{US} \$ / \mathrm{h}$ which is considerably less than the cost obtained by backtracking search algorithm [19]. Cost comparison, which can be found in Table 10, validates the efficiency of the presented approach.

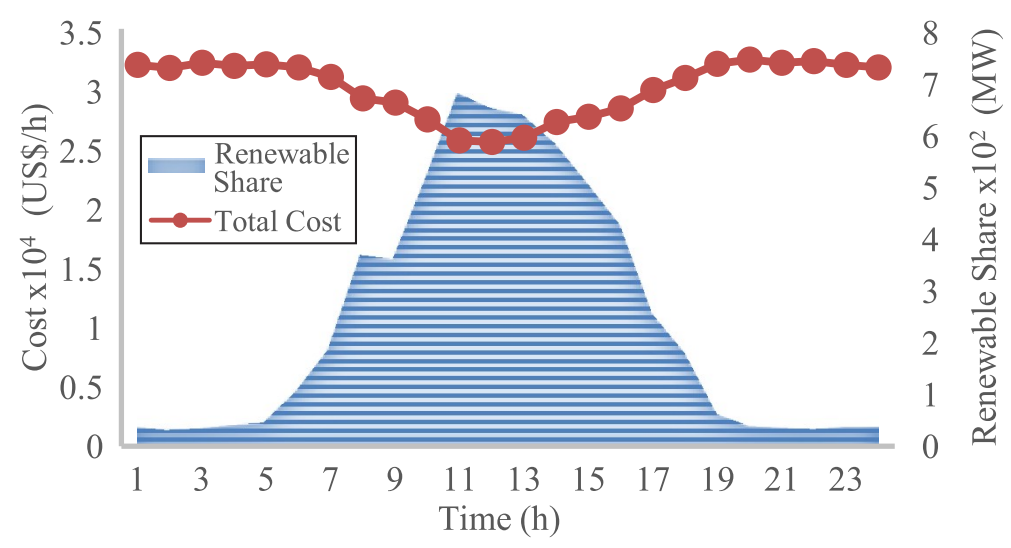

FIG. 6. EFFECT OF RENEWABLE SHARE ON COST- CASE STUDY-3

TABLE 9. COST COMPARSION FOR CASE STUDY-3

\begin{tabular}{|c|c|c|c|}
\hline Technique & CPSO & FPA & Cost Reduction (\%) \\
\hline Cost $(\$ / \mathrm{h})$ & $32,834.34$ & $30,360.875$ & 7.5 \\
\hline
\end{tabular}

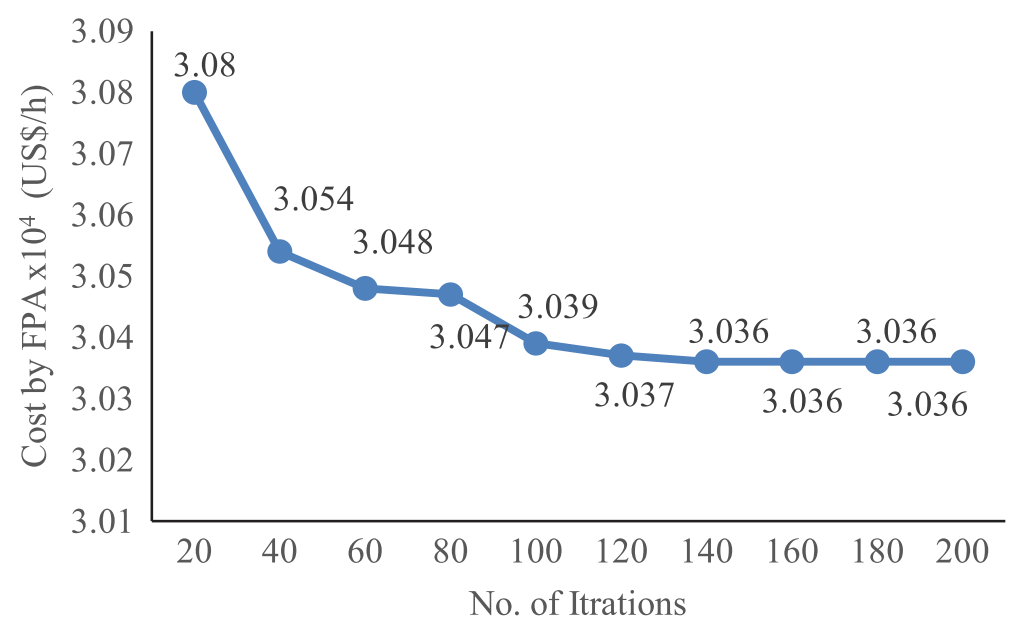

FIG. 7. CONVERGENCE OF SOLUTION FOR INCREASED NUMBER OF ITERATIONS

TABLE 10. COST COMPARSION FOR CASE STUDY-4

\begin{tabular}{|c|c|c|c|}
\hline Technique & BSA & FPA & Cost Reduction (\%) \\
\hline Cost $(\$ / h)$ & $40,608.8$ & $40,154.63$ & $1.2 \%$ \\
\hline
\end{tabular}

Mehran University Research Journal of Engineering \& Technology, Volume 38, No. 3, July, 2019 [p-ISSN: 0254-7821, e-ISSN: 2413-7219] 
Case Study-5: In this test case, 40 thermal generators are used. Fuel cost curves of these generators are nonconvex. ED of nonconvex and nonlinear functions is a complex problem.

Strength of algorithm is justified, when it is tested on this test system in which a wind plant and 13 solar units are integrated with 40 thermal units. Optimum cost obtained is $101808 \mathrm{US} \$ / \mathrm{h}$. Renewable energy resources produce a cheap and environment friendly power generation. Integration of wind and solar plants to the conventional generation system shares the total load demand among all the units. As a result, total cost of the system reduces to its minimum value.

\section{CONCLUSION}

In this paper, FPA is presented for the solution of EED of a power system integrated with solar and wind plants. The constraints of thermal generator power limits, power balance, transmission line losses, renewable energy power limits and ramp rate limits, are taken into account in the combined optimization problem. Case studies and their results prove that, larger share of renewable energy for a given power demand results in lower fuel costs, emission costs and the amount of emissions. Simulated results validate the satisfactory operation of proposed FPA. The results suggest that the cost of renewable energy resources is very small with respect to the thermal cost. Thus, the simulated results encourage the concept of integration of solar and wind plants to the conventional systems. The future work is expected to identify various other complex constraints such as spare capacity punishing cost of solar plants and prohibited operating zones etc. and then to integrate them in the economic dispatch problem.

\section{ACKNOWLEDGEMENT}

The authors would like to acknowledge the Power System Simulation Laboratory, Department of Electrical Engineering, University of Engineering \& Technology, Taxila, Pakistan, for providing lab resources to conduct research.

\section{REFERENCES}

[1] Conejo, A.J., and Baringo, L., "Unit Commitment and Economic Dispatch", Power System Operations, pp. 197-232, 2018.

[2] Khan, N.A., Awan, A.B., Mahmood, A., Razzaq, S., Zafar, A., Sidhu, G.A.S., and Member, I., “Combined Emission Economic Dispatch of Power System Including Solar Photo Voltaic Generation", Energy Conversion and Management, Volume 92, pp. 82-91, 2015.

[3] Xing, H., Lin, Z., and Fu, M., "Distributed Augmented Lambda-Iteration Method for Economic Dispatch in Smart Grid", Chinese Automation Congress, pp. 3302-3307, 2017.

[4] Azizipanah-Abarghooee, R., Dehghanian, P., and Terzija, V., "Practical Multi-Area Bi-Objective Environmental Economic Dispatch Equipped with a Hybrid Gradient Search Method and Improved Jaya Algorithm", IET Generation, Transmission \& Distribution, Volume 10, No. 14, pp. 3580-3596, 2016.

[5] Xu, T., Wu, W., Zheng, W., Sun, H., and Wang, L., "Fully Distributed Quasi-Newton Multi-area Dynamic Economic Dispatch Method for Active Distribution Networks", IEEE Transactions on Power Systems, 2017.

[6] Pan, S., Jian, J., and Yang, L., "A Mixed Integer Linear Programming Method for Dynamic Economic Dispatch with Valve Point Effect", arXiv Preprint arXiv:1702.04937, 2017. 
[7] Arango, D., Urrego, R., and Rivera, S., "Economic Dispatch in Microgrids with Renewable Energy Using Interior Point Algorithm and Lineal Constrainst", Ingeniería y Ciencia, Volume 13, No. 25, pp. 123-152, 2017.

[8] Haruna, Y., Yisah, Y., Bakare, G., Haruna, M., and Oodo, S., "Optimal Economic Load Dispatch of the Nigerian Thermal Power Stations Using Particle Swarm Optimization", The International Journal of Engineering and Science, Volume 6, No. 1, pp. 17-23, 2017.

[9] Augusteen, W., Geetha, S., and Rengaraj, R., "Economic Dispatch Incorporation Solar Energy using Particle Swarm Optimization", Electrical Energy Systems, pp. 67-73, 2016.

[10] Ouyang, Y., Niu, Q., and Zhang, Y., “Combined Heat and Power Economic Dispatch Using Differential Evolution", International Conference on Network, Communication and Computing, pp. 222-226, 2017.

[11] Subathra, M., Selvan, S.E., Victoire, T.A.A., Christinal, A.H., and Amato, U., "A Hybrid With Cross-Entropy Method and Sequential Quadratic Programming to Solve Economic Load Dispatch Problem", IEEE Systems Journal, Volume 9, No. 3, pp. 1031-1044, 2015.

[12] Aydin, D., Yavuz, G., Özyön, S., Ya ar, C., and Stützle, T., "Artificial Bee Colony Framework to Non-Convex Economic Dispatch Problem with Valve Point Effects: A Case Study", Proceedings of the Genetic and Evolutionary Computation Conference Companion, pp. 1311-1318, 2017.

[13] Wilas, J., Maœniak, R., Daniszewski, P., and Jadczak, P., "Renewable Energy Sources Today and Tomorrow", World Scientific News, Volume 60, pp. 103-112, 2016.

[14] Brini, S., Abdallah, H. H., and Ouali, A., "Economic Dispatch for Power System Included Wind and Solar Thermal Energy", Leonardo Journal of Sciences, Volume 14, No. 2009, pp. 204-220, 2009.
[15] ElDesouky, A.A., "Security and Stochastic Economic Dispatch of Power System Including Wind and Solar Resources with Environmental Consideration”, International Journal of Renewable Energy Research , Volume 3, No. 4, pp. 951-958, 2013.

[16] Jeddi, B., and Vahidinasab, V., “A Modified Harmony Search Method for Environmental/Economic Load Dispatch of Real-World Power Systems”, Energy Conversion and Management, Volume 78, pp. 661-675, 2014.

[17] Yang, X.-S., Karamanoglu, M., and He, X., "MultiObjective Flower Algorithm for Optimization”, Procedia Computer Science, Volume 18, pp. 861-868, 2013.

[18] Nabil, E., "A Modified Flower Pollination Algorithm for Global Optimization", Expert Systems with Applications, Volume 57, pp. 192-203, 2016.

[19] Tyagi, N., Dubey, H.M., and Pandit, M., "Economic Load Dispatch of Wind-Solar-Thermal System using Backtracking Search Algorithm”, International Journal of Engineering, Science and Technology, Volume 8, No. 4, pp. 16-27, 2016.

[20] Shilaja, C., and Ravi, K., "Optimization Of Emission/ Economic Dispatch using Euclidean Affine Flower Pollination Algorithm and Binary FPA in Solar Photo Voltaic Generation”, Renewable Energy, Volume 107, pp. 550-566, 2017.

[21] Qi, Z., Zhenshu, W., Yunpeng, S., and Shichao, Q., "The Optimal Dispatch with Combination of Wind Power and Photovoltaic Power Systems", Energy Procedia, Volume 103, pp. 94-99, 2016.

[22] Alavi, O., Mohammadi, K., and Mostafaeipour, A., "Evaluating the Suitability of Wind Speed Probability Distribution Models: A Case of Study of East And Southeast Parts of Iran", Energy Conversion and Management, Volume 119, pp. 101-108, 2016. 
[23] Abdelaziz, A., Ali, E., and Elazim, S.A., "Combined Economic and Emission Dispatch Solution using Flower Pollination Algorithm", International Journal of Electrical Power \& Energy Systems, Volume 80,pp. 264274, 2016.

[24] Panigrahi, C., Chattopadhyay, P., Chakrabarti, R., and Basu, M., "Simulated Annealing Technique for Dynamic Economic Dispatch", Electric Power Components and Systems, Volume 34,No.5, pp. 577-586, 2006.
[25] Cai, J., Ma, X., Li, L., and Haipeng, P., "Chaotic Particle Swarm Optimization for Economic Dispatch Considering the Generator Constraints", Energy Conversion and Management, Volume 48,No.2, pp. 645-653, 2007.

[26] He, D., Wang, F., and Mao, Z., “A Hybrid Genetic Algorithm Approach Based on Differential Evolution for Economic Dispatch with Valve-Point Effect", International Journal of Electrical Power \& Energy Systems, Volume 30,No.1, pp. 31-38, 2008. 